\title{
$¿$ What is the outcome of Nonfunctioning Pituitary Adenomas (NFPAs) after surgery and are there any factors to predict it? : A Multicenter Study in Northern Spain.
}

Rodriguez Caballero M.G. ${ }^{1}$, Valdés Gallego N. ${ }^{1}$, Ares J. ${ }^{1}$, Larrañaga I. ${ }^{2}$, Hernández C. ${ }^{3}$, Ollero D. ${ }^{3}$, Gaztambide S. ${ }^{2}$, Isasa L. ${ }^{2}$, Forga L. ${ }^{3}$, Mouritz M. ${ }^{3}$, Suárez L. ${ }^{1}$, Rodriguez R. ${ }^{3}$, Corte D. ${ }^{1}$, Delgado E. ${ }^{1}$, Sánchez Ragnarsson C. ${ }^{1}$, Cacho L. ${ }^{1}$, Menéndez Torre E. ${ }^{1}$

1. Servicio de Endocrinología y Nutrición del Hospital Universitario Central de Asturias.

2. Servicio de Endocrinología y Nutrición del Hospital Universitario de Cruces. Bilbao.

3. Servicio de Endocrinología y Nutrición del Complejo Hospitalario de Navarra.

\section{METHODS}

\section{OBJECTIVES}

Retrospective cohort analysis of 164 patients with NFPAs from 3 different centers in Northern Spain who underwent surgery between 1987-2014. The main outcomes were R/P rate during follow-up using Kaplan-Meier estimator and the univariate and multivariate analysis of risk factors that could be involved with $R / P$.

There is scarcity of data on the recurrence and/or progression (R/P) rate in NFPAs after surgery and the risk factors that can predict this outcome. So the aim of this study was to analyze a large series of NFPAs with a long follow-up after surgery, focusing on the evaluation of $R / P$ rate and the risk factors associated with it.

\section{RESULTS}

$\mathrm{R} / \mathrm{P}$ was detected in 70 patients (43\%) after surgery, over a median clinical follow-up of 8 years (1-27), the median time to R/P was 4.1 years. Recurrence-free survival was $65 \%, 49 \%, 42 \%$ and $32 \%$ at $5,10,15$ and 20 years after surgery, respectively. The univariate analysis identified the following R/P risk factors: pituitary apoplexy and visual impairment at diagnosis; and as protective factor: RT after surgery in patients with subtotal resection (STR) but the multivariate Cox analysis only confirmed as independent factors: visual impairment (hazard ratio [HR] 2.1, 95\% confidence interval $[\mathrm{Cl}] 1.1-4.2 ; \mathrm{p}=0,02)$ and $\mathrm{RT}$ in patients with STR after surgery (HR 0.4, 95\% Cl 0.21-0.89; $p=0.02$ ).

\section{Kaplan- Meier estimates of Recurrence and /or Progression (R/P)}
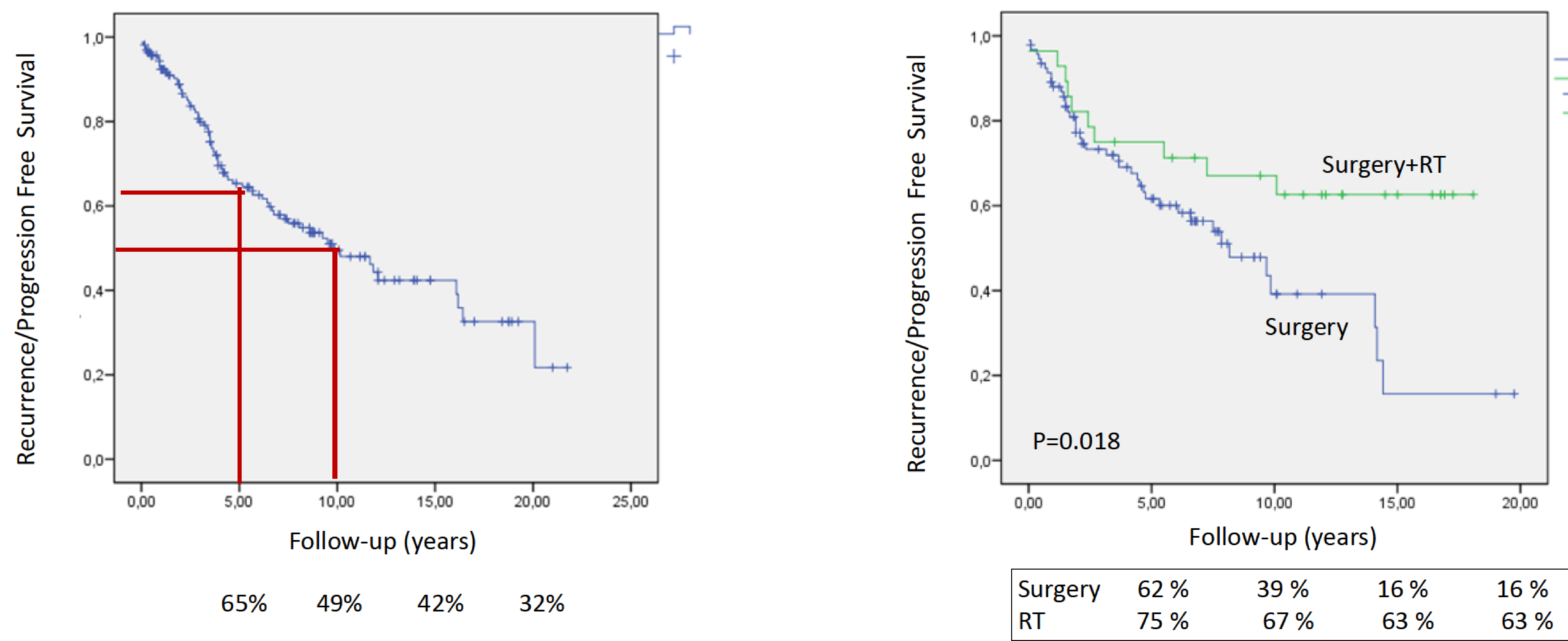

\section{CONCLUSIONS}

Long term follow-up in NFPAs after surgery is mandatory because R/P occurs in a large percentage of these patients and the risk does not disappear in the long term. Our study suggests that this follow-up has to be more rigorous in patients with visual impairment at diagnosis because they have the highest risk of R/P. RT could decrease this risk specially in those patients with subtotal tumor resection. 